\title{
Causality between external balance and (some) fiscal variables: Preliminary results for the Eurozone
}

\author{
Carlos Alberto Carrasco* \\ Departamento de Economía, Universidad de Monterrey, México
}

Received: 20 May 2016

Revised: 20 September 2016

Accepted: 5 October 2016

\begin{abstract}
In this article, we present preliminary results, analyzing the causality between external balance and fiscal variables (primary public balance, interest paid on debt and overall public balance) within the so-called twin deficits hypothesis for a set of six Eurozone countries - three core countries (Austria, Finland and Germany) and three peripheral countries (Greece, Portugal and Spain) - in the period 1972-2011. We implement the Toda and Yamamoto (1995) approach to Granger non-causality testing (Granger, 1969). Results are not homogeneous for all the Eurozone countries included in the sample. Evidence of causality according to the twin deficits hypothesis is provided only for the case of Austria. In addition, evidence of a causal relationship from interest paid on debt to external balance is provided in the case of Portugal and from external balance to interest paid on debt for Austria and Germany.
\end{abstract}

Keywords: Eurozone external imbalances; twin deficits hypothesis; causality testing. JEL Classification Codes: H62, F32, F41

\section{Introduction}

After the beginning of the global financial crisis, an increased attention has been paid to the external imbalances among Eurozone countries, due to its possible link with the outbreak of the crisis and their potential effects on the (in)stability of the Eurozone (Brissimis, et al., 2012; Campa and Gavilán, 2011; Chen et al., 2013; Gehringer, 2015). However, it was up to the burst of the European sovereign debt crisis, when research and policy articles have increased their focus on the relationship between the external imbalances and the fiscal position of government budgets (Brissimis et al., 2012; Hein et al., 2012) and the causality between them within the socalled twin deficits hypothesis (Algieri, 2013; Bluedorn and Leigh, 2011).

Twin deficits hypothesis refers to the positive macroeconomic relationship between current account balance and government budget balance, which was originally used to analyze the

\footnotetext{
*E-mail: carlos.carrasco@udem.edu.

Citation: Carrasco, C.A. (2016) Causality between External Balance and (Some) Fiscal Variables: Preliminary Results for the Eurozone, Economics and Business Letters, 5(3), 80-86.
} 
United States (U.S.) trade deficit during the 1980s and 1990s (Gordon, 1986). In twin deficits hypothesis, causality goes from government budget balance to external balance. In this regard, Salvatore (2006:701-702) clearly summarizes the transmission channel of the twin deficits hypothesis:

\section{"[T] he theoretical [twin deficits hypothesis] relationship links casually an increase in the budget deficit to an increase in domestic interest rates, to an inflow offoreign capital, to the appreciation of the domestic currency, which then results in a current account deficit."}

Research on the relationship between external balance and fiscal balance for Eurozone member states has shown some interesting results. For instance, that the relationship between both balances is not homogeneous for all Eurozone countries, that is, for some countries, this relationship exists, while in the case of other countries, there is not supporting evidence of this relationship (Algieri, 2013; Brissimis et al., 2012; Hein et al., 2012). In addition, when this relationship exists, it is not one-to-one (Barnes et al., 2010; Bluedorn and Leigh, 2011). Moreover, in a context of interdependence, there is a need for fiscal coordination among Eurozone member states but not for a uniform fiscal policy (Kosteletou, 2013). Finally, external imbalances have been originated - at least in some countries, e.g., Spain - in private savingsinvestment decisions, where fiscal deficits were observed after the outbreak of the financial crisis in order to smooth the effects of private deleverage process (Hein et al., 2012).

In regard of the twin deficits hypothesis for Eurozone countries, results are not conclusive but contradictory. Two articles can exemplify this. On the one hand, Kosteletou (2013) shows evidence supporting twin deficits hypothesis in deficit and surplus countries within a panel data framework. On the other hand, Algieri (2013) points out that, at least for Southern Eurozone countries, there is not a clear nexus between fiscal balance and external balance. In this regard - and before going to the econometric analysis - we would like to highlight some points. First, in both cases, the focus of analysis is in Southern Eurozone countries. Second, both articles employ different techniques that would be a signal of the sensibility of results to the methodological strategy. Finally, it is necessary to know the role of public finance in the existence of external imbalance in order to implement policy actions to correct those imbalances in the medium and long term.

In what follows, we present preliminary results of the empirical analysis of the causal relationship between external imbalances and some fiscal variables for six Eurozone countries in the period 1972-2011. To this aim, we implement the Toda and Yamamoto (1995) approach to Granger causality testing (Granger, 1969), which allows including variables with different order of integration without the need to differentiate the series to reach stationarity. Some novelties of this article are the use of the Mauro et al. (2013) database - which decomposes the overall fiscal balance in primary balance and interest paid on public debt - in a longer span of time than the above-mentioned studies for a set of countries, including core and peripheral countries. We would like to reiterate that what we present here are preliminary results within a wider research project on the determinants of Eurozone external imbalances, in general, and the role of public finance, in particular.

\section{Data and methodology}

We focus on the analysis of twin deficits hypothesis in six Eurozone countries - three core countries (Austria, Finland and Germany) and three peripheral countries (Greece, Portugal and Spain) - for the period 1972-2011. As stated above, in twin deficits hypothesis, causality goes from fiscal variables to external balance. Thus, we aim to test this hypothesis of causality in the euro area.

We use data from the macro-economic database (AMECO) for the external balance (hereinafter EB) proxied by the balance on current transactions with the rest of the world, which 
is the sum of net exports of goods and services, net primary income and net current transfers, the latter two from the rest of the world. In the case of fiscal variables, we use the series of the database from Mauro et al. (2013). Mauro et al. (2013) database contains historical data for government primary balance (hereinafter PB), interest paid on public debt (hereinafter IE) and overall government balance (hereinafter $\mathrm{CB}$, difference between $\mathrm{PB}$ and IE).

Data is available for all the series with an annual frequency for the period 1960-2011. However, we shorten the sample in order to avoid biased results due to the shock of the end of Bretton Woods. Therefore, our analysis focuses on the period 1972-2011. In addition, we implement Bai-Perron breakpoint tests (Bai 1997; Bai and Perron 1998, and critical values from Bai and Perron 2003) to identify structural changes in the EB series (see Table 1). Those breakpoints for each country were introduced in the VAR estimations as exogenous dummy variables.

Table 1. Breakpoint tests for EB series.

\begin{tabular}{lr}
\hline \hline Austria & $1982,1994,2002$ \\
Finland & $1989,1995,2003$ \\
Germany & $1979,1991,2004$ \\
Greece & 1982,1998 \\
Portugal & 1978,1984 \\
Spain & 2005 \\
\hline \hline
\end{tabular}

Note: * L+1 vs L sequentially determined breaks; auxiliary regression including a constant and a trend as regressors.

In our empirical analysis, we study causality ${ }^{1}$ between fiscal variables (primary budget balance, interests paid on debt and overall budget balance) and external balances using the Toda and Yamamoto (1995) approach to Granger causality testing (Granger, 1969). In TodaYamamoto approach, VAR estimations are augmented with extra lags, depending on the maximum order of integration of the series within the group. An advantage of this approach is that it can be implemented in levels, even when variables are not stationary.

Following Toda-Yamamoto approach, we apply the usual lag selection, based on Schwartz and Akaike information criteria (we select the higher lag length of both tests). The order of integration is determined using augmented Dickey-Fuller (Dickey and Fuller 1979, 1981; hereinafter ADF) and Phillips-Perron (Phillips and Perron 1988; hereinafter PP) unit root tests. Let $k$ be the lag length and $d_{\max }$ the maximum order of integration within the group. Before implementing Granger restrictions, we estimate a VAR model of order $k$, and if there is evidence of serial correlation, we increase the lag length until no evidence of serial correlation is found. Subsequently, a $\left(k+d_{\text {max }}\right)$ th order VAR model is estimated. Granger-type restrictions are tested on the first $k$ coefficients ${ }^{2}$ while last $d_{\text {max }}$ lagged vectors are ignored.

\section{Results}

We implement Granger non-causality testing in three groups of variables: Group 1 includes EB and PB, Group 2 includes EB and IE, and Group 3 includes EB and CB. Table 2 summarizes $\mathrm{ADF}$ and PP unit root tests applied to EB, PB, IE and CB. As shown in Table 2, the maximum order of integration $d_{\max }$ for all VAR groups is 1 with the only exception for the case of Portugal in Group 3. Thus, EB is I(1) for all countries excluding Portugal; PB is I(1) for all countries excluding Austria and Germany; IE is I(1) for all countries; and CB is I(1) for Finland, Greece and Spain, and I(0) for Austria, Germany and Portugal.

\footnotetext{
${ }^{1}$ In econometrics, Granger causality implies the ability to better predict another variable using the history of both variables.

${ }^{2}$ Or $k$ plus the number of extra lags included until found no serial correlation.
} 
Table 2. Unit Root Tests.

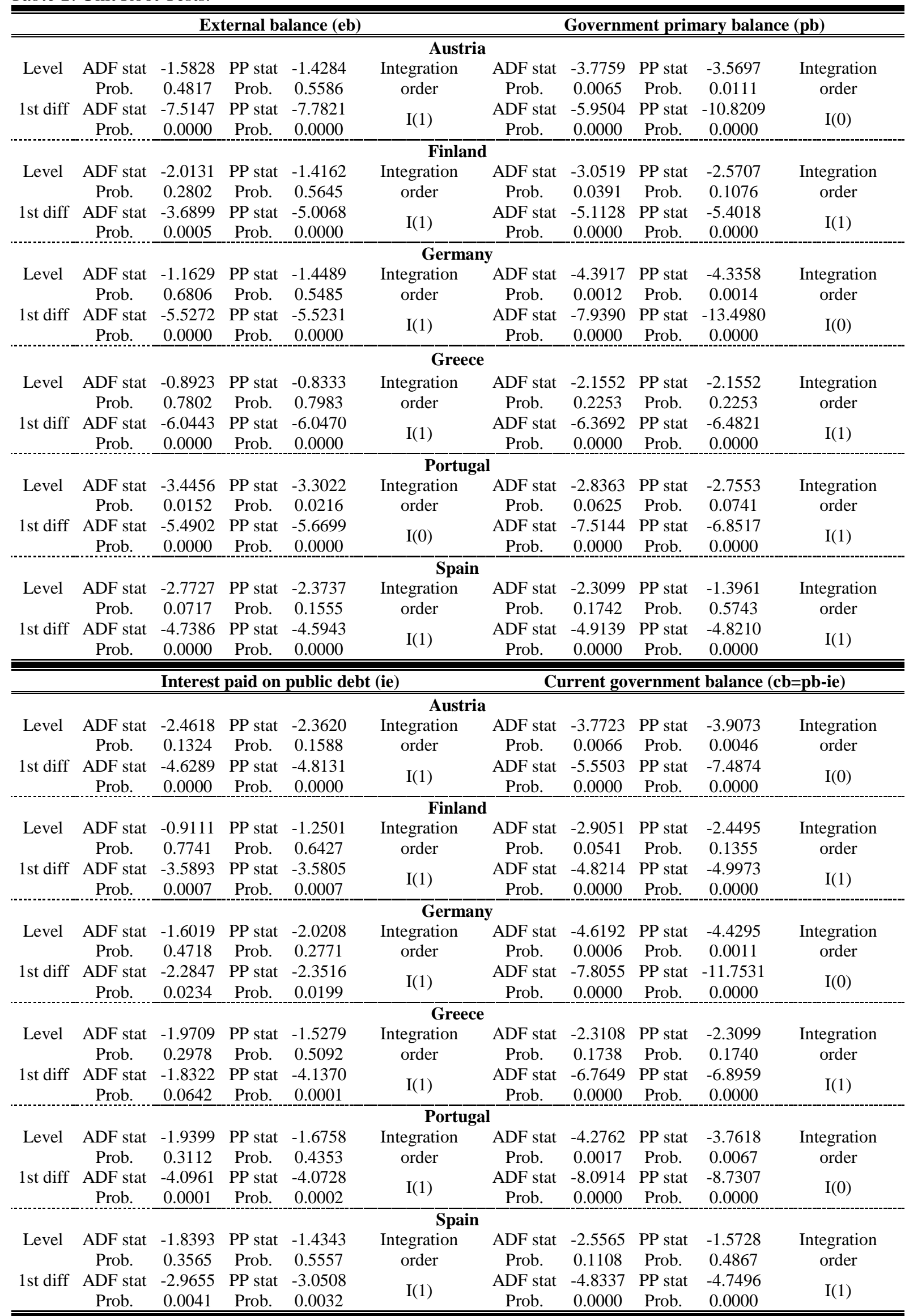

Note: SIC was used for lag length selection for ADF. In the case of PP, spectral estimation method using Bartlett kernel and Newey-West for bandwidth. Estimated with constant in levels and without exogenous variables in 1st difference. 
Table 3 summarizes results of Toda-Yamamoto approach to Granger non-causality. ${ }^{3}$ The null of non-causality from fiscal variables to external balance is only rejected at $5 \%$ for the case of Austria in Group 1 and Group 3, and for Portugal in Group 2. According to the twin deficits hypothesis, direction goes from fiscal variables to external balance. However, with the only two exceptions of Austria and Portugal there is no evidence supporting this hypothesis.

In the case of reverse causality, rather than what is expressed in twin deficits hypothesis, that is, from external balance to fiscal variables, results are not homogeneous among Eurozone countries. For Austria and Germany, the null of non-causality is rejected for Group 2 (EB does not Granger cause IE).

Table 3. Toda-Yamamoto approach to Granger non-causality.

\begin{tabular}{cccc}
\hline \hline & Group 1: EB and PB & Group 2: EB and IE & Group 3: EB and CB \\
\hline \hline & H0: PB does not Granger cause EB & H0: IE does not Granger cause EB & H0: CB does not Granger cause EB \\
Austria & Null rejected & Null not rejected & Null rejected \\
Finland & Null not rejected & Null not rejected & Null not rejected \\
Germany & Null not rejected & Null not rejected & Null not rejected \\
Greece & Null not rejected & & Null not rejected \\
Portugal & Null not rejected & Null rejected & Null not rejected \\
Spain & Null not rejected & Null not rejected & Null not rejected \\
\hline \hline & H0: EB does not Granger cause PB & H0: EB does not Granger cause IE & H0: EB does not Granger cause CB \\
Austria & Null not rejected & Null rejected & Null not rejected \\
Finland & Null not rejected & Null not rejected & Null not rejected \\
Germany & Null not rejected & Null rejected & Null not rejected \\
Greece & Null not rejected & & Null not rejected \\
Portugal & Null not rejected & Null not rejected & Null not rejected \\
Spain & Null not rejected & Null not rejected & Null not rejected \\
\hline \hline
\end{tabular}

Note: Details of estimations upon request to the authors.

Summarizing, results are not homogeneous for the six Eurozone countries, or when analyzing causality from fiscal variables to external balance or when inverse causality is tested. In addition, results support twin deficits hypothesis in the case of Austria and Portugal. In the case of reverse causality, evidence for the cases of Austria and Germany is provided.

\section{Concluding remarks}

In this article, we present preliminary results, analyzing the causality between external balance and fiscal variables (primary public balance, interest paid on debt and overall public balance) within the so-called twin deficits hypothesis for a set of six Eurozone countries - three core countries (Austria, Finland and Germany) and three peripheral countries (Greece, Portugal and Spain) - in the period 1972-2011, using the Toda and Yamamoto (1995) approach to Granger non-causality testing (Granger, 1969). The importance of studying the causal relationship between the external balance and fiscal balance lies in the possibility of implementing fiscal measures to permanently reduce external imbalances in the medium and long term.

Results are not homogeneous for all the Eurozone countries included in the sample. Evidence of causality, according to twin deficits hypothesis, is provided for the cases of Austria (Group 1 and 3) and Portugal (Group 2), while reverse causality was found in the case of Austria and Germany for Group 2.

In regard of our results, there are some points that should be highlighted. First, the relationship between external balance and fiscal balance is not homogeneous among our sample of countries. Second, with the only exception of Austria, all the analyzed countries do not present evidence on the causal relationship between external balance and fiscal deficits (primary

\footnotetext{
${ }^{3}$ In the case of Greece for Group 2 (EB and IE), results are not dynamically stable. For this reason, we exclude Group 2 for Greece from the analysis.
} 
and overall deficit). Apart from the Austrian case, the causal relationships for Germany and Portugal are found in Group 2 (EB and IE). In the German case, there is evidence of a continuous (but moderate) increase in interests paid on public debt between 1972 and 1983. After 1983, interest paid on public debt is stabilized up to the German reunification when another increase in interest paid on public debt is presented. Those historical shocks require a detailed analysis focusing on short-term periods. However, given the number of observations, the analysis would require another statistical technique.

What factors could explain the results? Why the results show no supportive homogeneous evidence of the twin deficits hypothesis? The answer to both questions is related to the existence of multiple determinants of external imbalances in the euro countries. On the one hand, as stated by Hein et al. (2012), external imbalances have been (mainly) originated in private savingsinvestment decisions, where fiscal deficits were observed after the outbreak of the financial crisis in order to smooth the effects of private deleverage process. On the other hand, recent economic literature has highlighted some factors behind the European external imbalances: the expected catching-up process (Gehringer 2015; Belke and Dreger 2013), differences in price and non-price competitiveness (Belke and Dreger 2013, Arghyrou and Chortareas 2008) and the development of the financial system (Gehringer 2015; Schmitz and von Hagen 2011).

While the outcome presented here is preliminary, these results give us an idea of the complexity of the relationship between the external balance and the public balance in the case of Eurozone countries. In our ongoing works, we are aiming to deepen and strengthen the results presented here.

Acknowledgements. The research leading to these results has received funding from Consejo Nacional de Ciencia y Tecnología (CONACyT, Mexico) under the grant for Postdoctoral Researchers and by the Sistema Nacional de Investigadores (CONACyT-SNI). We thank comments by an anonymous referee.

\section{References}

Algieri, B. (2013) An empirical analysis of the nexus between external balance and government budget balance: The case of the GIIPS countries, Economic Systems, 37, 233-253.

Arghyrou, M.G. and Chortareas, G. (2008) Current Account Imbalances and Real Exchange Rates in the Euro Area, Review of International Economics, 9(5), 747-764.

Bai, J. (1997) Estimating multiple breaks one at a time, Econometric Theory, 13(3), 315-352.

Bai, J. and Perron, P. (1998) Estimating and testing linear models with multiple structural changes, Econometrica, 66(1), 47-78.

Bai, J. and Perron, P. (2003) Critical values for multiple structural change tests, Econometrics Journal, 6(1),72-78.

Barnes, S., Lawson, J. and Radziwill, A. (2010) Current Account Imbalances in the Euro Area: A Comparative Perspective, Organization for Economic Co-operation and Development Economics Department Working Paper 826.

Belke, A. and Dreger, C. (2013) Current Account Imbalances in the Euro Area: Does Catching up Explain the Development, Review of International Economics, 21(1), 6-17.

Bluedorn, J.C., and Leigh, D. (2011) Revisiting the Twin Deficits Hypothesis: The Effect of Fiscal Consolidation on the Current Account, IMF Economic Review, 59(4), 582-602.

Brissimis, S.N., Hondroyiannis, G., Papazoglou, C., Tsaveas, N.T., and Vasardani, M.A. (2012) Current Account determinants and external sustainability in periods of structural change, Economic Change and Restructuring, 45, 71-95.

Campa, J.M. and Gavilán, A. (2011) Current Accounts in the Euro Area: An Intertemporal Approach, Journal of International Money and Finance, 30(1), 205-228.

Chen, R., Milesi-Ferretti, G.M., and Tressel, T. (2013) External imbalances in the Eurozone, Economic Policy, 28(73), 101-142. 
Gehringer, A. (2015) New evidence on the determinants of current accounts in the EU Empirica, 42(4), 769-793.

Dickey, D.A. and Fuller, W.A. (1979) Distribution of the Estimator for Autoregressive Time Series with a Unit Root, Journal of the American Statistical Association, 74(366), 427431.

Dickey, D.A. and Fuller, W.A. (1981) Likelihood Ratio Statistics for Autoregressive Time Series with a Unit Root, Econometrica, 49(4), 1057-1072.

Gordon, R.J. (1986) U.S. fiscal deficits and the world imbalance of payments, Hitotsubashi Journal of Economics, 27, 7-41.

Granger, C.W.J. (1969) Investigating Causal Relations by Econometric Models and CrossSpectral Methods, Econometrica, 37, 424-438.

Hein, E., Truger, A., and van Treeck, T. (2012) The European Financial and Economic Crisis: Alternative Solutions from a (Post-) Keynesian Perspective In Arestis, P. and Sawyer, M. (Eds.): The Euro Crisis. Palgrave Macmillan: Basingstoke, 35-78.

Kosteletou, N. (2013) Financial integration, euro and the twin deficits of Southern Eurozone countries, Panoeconomicus, 60(2), 161-178.

Mauro, P., Romeu, R., Binder, A., and Zaman, A. (2013) A modern history of fiscal prudence and profligacy, IMF Working Papers WP/13/5.

Phillips, P.C.B. and Perron, P. (1988) Testing for a Unit Root in Time Series Regression, Biometrika, 75(2), 335-346.

Salvatore, D. (2006) Twin deficits in the G-7 countries and global structural imbalances, Journal of Policy Modeling, 28, 701-712.

Schmitz, B. and von Hagen, J. (2011) Current Account Imbalances and Financial Integration in the Euro Area, Journal of International Money and Finance, 30(8), 1676-1695.

Toda, H.Y. and Yamamoto, T. (1995) Statistical inferences in vector autoregressions with possibly integrated processes, Journal of Econometrics, 66, 225-250. 